\title{
Confluences between Art and Sport
}

\author{
Danny Shorkend \\ WIZO School of Design, Haifa, Israel \\ Email: dannyshorkend@yahoo.co.uk
}

How to cite this paper: Shorkend, D. (2019). Confluences between Art and Sport. Advances in Physical Education, 9, 87-102. https://doi.org/10.4236/ape.2019.92007

Received: February 22, 2019

Accepted: March 19, 2019

Published: March 22, 2019

Copyright $\odot 2019$ by author(s) and Scientific Research Publishing Inc. This work is licensed under the Creative Commons Attribution International License (CC BY 4.0).

http://creativecommons.org/licenses/by/4.0/

\begin{abstract}
In this article, I present various ways of looking at sport through the lens of art-aesthetic concepts. It is argued that indeed there are overlaps between art and sport and that this suggests a complementary pairing between the two that in turn sets in motion other such pairings, such as that between the aesthetic and the extra-aesthetic. In short: art and sport are both games within a certain defined cultural setting, but also interlink. I then conclude that since there are theoretical links, there may be practical implications.
\end{abstract}

\section{Keywords}

Art, Sport, Movement, Physicality, Aesthetic, Games

\section{Introduction}

When a painter paints, there are obviously different methods, but the common fact of the matter is a movement of some sort. Some movements may be more vigorous and gestural, others more subtle and careful. But what motivates the stroke? How is it that a certain style may evolve? If the painter moves the way he/she does, he/she expresses an emotional, intellectual or primitive impulse, and then the stroke contains such energy. In addition, circumscribed by and within the game, we call "painting" and art. The stroke may carry a certain meaning. That is, it is a recognised cultural expression. Within the particular art-work itself, the artist also intends that stroke eventually leads to an end, a completion toward the product that we call a painting or art-work.

In general, sport also requires a complicated set of movements, that differs from sport to sport and within a particular sport, from individual to individual or even between various teams. One may also dub that movement as an expression of energy, an energy similar to art in that it is emotive and primitive. But is it similarly intellectual? I am not sure if one could describe the craft of art (and here we might also speak of the craft of sport) as intellectual. In not being intel- 
lectual as such or in their practical doing as it were, this does not discount that both art and sport convey an idea. That is, the will of the sportsperson and the will of the artist express something through their particular craft, via movement of some kind (even though conceptual art is visceral in some way, at the very least there is a sensory component).

So that when the painter makes a certain stroke, instantiates a skill, it involves the mind and the body guided by a certain will, albeit at times a sub-conscious impulse. Similarly a good sportsperson is said to be "in the zone" when engaged in a particular play. The success of both artist and sportsperson then is the application of learned behaviours in changing circumstances within the game, the game defined as a particular art form or sport. Such behaviours both establish a certain aesthetic as well as meanings in a given culture-its extra-aesthetic content if you like. If we can so draw such confluences between these cultural expressions, could it be that teaching art to sports men and women assists in improving their sporting performance? In other words, one might describe art and sport as an instance of a complementary pairing which further establishes another complementary pair, namely between that of the aesthetic and that of the extra-aesthetic. In so arguing, it may be that arts awareness on the part of the sportsperson may enhance their athletic performance.

By complementary pairings, I wish to express the idea that knowledge of one variable, say the aesthetic is inversely proportional to knowledge of the other variable, the extra-aesthetics. The principle of complementary is the 1927 Copenhagen interpretation by Bohr of the quantum duality of light as both a wave and particle, which I am now applying in a different context. Other such pairing may also obtain such as: modernism:postmodernism; science:humanaties; empericism:rationalism; play:struggle; being:becoming; idea:form; thought:action; body:mind; analytical philosophy:continental philosophy; socialism:capatalism; fact:value; simple:complex; movement:stasis; culture:nature; thought:emotion; games:life; physicality:spirituality; literal:figurative and so on and so forth-all of which play a part in both art and sport and beyond. A harmonious integration of these "polarities" may lead to greater health. Another aspect of these complementary pairings is that we cannot say which "side" is true and which "side" false, because they are incommensurate language games. Since, in accord with Kripke's (1982) rule-following paradox one can say that any action could be seen to accord with a rule, so that anything could mean anything, that is, that the sign does not correspond to only one referent (or any referent). That being so, it may appear that complementary pairings may be fated wherein there is no relationship between either one of the pairs, for example if we were to say one side is "true" and the other "false". Yet, since we are not talking of opposites as such but simply complementary pairings, there is a relationship and an oscillation - a creative, enriching one - between them so that it is conceivable for example that art is related to sport in that both are partially aesthetic, neither "purely" aesthetic nor "purely" extra-aesthetic. The limits of what we can know are merely a surface masking another level (and so on ad infinitum or at the point of a "singular- 
ity"), a kind of structural-post-structural oscillation. Yet within either "side" of one of the complementary pairings is its relationship to the other "side". In post modern verbiage we might say that there is only the bodily "surface" or text whose signs may be read as corresponding to a particular language-game-as meaning something-but with no ultimate description and correspondence to "reality". Art is one such "surface" open to interpretation; sport another. Both share an aesthetic and antithetically, an extra-aesthetic dimension. I propose answering the question in what way can art, that which is partially aesthetic lead to an understanding of why sport ought to be considered partially aesthetic. How then can art be useful in extending the everyday aesthetic of sport? First we need to define art and then see in what way it may relate to sport, which also needs to be defined somewhat.

While art may have existed circa 30,000 years ago, it had a different meaning and value to the modern or post modern concept of art. Today, we look at fine art from a number of perspectives: it may form no part of magic as in securing a good hunt or venerating gods. But it does fulfill other "magical" functions in our lives. Art still tells stories, honors and reflects on life-issues. But perhaps most significant, since Baumgautun, art has been associated with what has come to be known as the aesthetic. The aesthetic refers to delight in the sensory qualities that an art-object conjures in the viewer and following Kant (1952) that elicits a "disinterested" pleasure as the viewer appreciates the object as form unto itself. This position, though, following the Institutional theory and artists such as $\mathrm{Du}$ champ, Kosuth and Warhol was undermined as art and aesthetics were now, or so it was argued, no longer one and the same thing; art not necessarily being the exemplary instance of what the aesthetic is. Moreover, revisionist art history and theory sought to supplant the aesthetic "presence" by explaining art as mere ideological construction, historically contingent so that as Derrida (1984) might have it, the sign is but a "trace"-the art object thus incomplete, relative, part of a process and decentred. What are we then left with today when we consider art or rather fine art? It would seem a radical "anything goes" attitude with theories and histories and practice that tend to either an aesthetic description or tending to an extra-aesthetic one with subtle nuances "between" these complementary poles. For example, feminist critique deals with the politics and social ideology that informs a certain kind of aesthetic, say of the nude in Western art; a Marxist critique may reduce art-talk to economic-talk and in the process describe the aesthetics of the art-object in terms of "bougiouse taste"; or a formalist description which tends to the aesthetic and eschews other non-exhibited properties, such as politics, history, economics and so on and so forth. In practice, we might have hybrid forms of art, such as something which is at once painterly and sculptural or decades ago in the 1960 's, for example, the use of nature as art as in land and environmental art in order to broaden the definition of art and deconstruct time-honored values such as the sacrosanct nature of the art gallery, permanence and art as commodity-object.

Sport too can be "traced" to hunting roots, but clearly like the notion of the 
aesthetic that pertains to art, sport as the phenomenon we now know it is rather more recent. Only rather recently do we find much academic literature concerning sport-sociology, history, philosophy, health sciences and other disciplines. Of course the Ancient Greeks were an important exception. In the last few years a healthy debate has arisen as to whether or not the everyday, of which sport (being so common) is an example, can be considered as an aesthetic modality.

The "aesthetics of the everyday", a new sub-discipline in aesthetics, falls in to two camps: the "strong" and "weak" form. The "strong" form argued as Saito $(2007,2010)$, Melchionne $(2011,2013)$ and others do, that art aesthetics and everyday aesthetics are separate realms completely, whereas the "weak" version that Dowling (2010), Ratiu (2013) and others subscribe to states that art aesthetics may be useful in extending everyday aesthetics. I side with the latter position and thence explore ways in which traditional art aesthetics can do just that. So given their common aesthetic dimension and by implication the oscillation with the extra-aesthetic as a complementary pair, I shall now demonstrate in a cursory manner some ways in which art aesthetics extends sports aesthetics. These are general categories to introduce the reader to the reasonableness of such a claim. I first explain each concept as applied to art and then show a parallel understanding of sport. In thus relating the two, the potential for a creative oscillation ensues.

\section{Movement (As Artist/Sportsperson and Audience)}

When considering art, ranging, for example, from dance to painting, sculpture to poetry, music to installation and new media and so on, it is clear that there is always an element of some kind of movement. For example, in painting, the artist dexterously moves his or her arm, wrist or body in order to make a mark. Even the viewer can see in the finished product or painting, the energy expressed in the artist's movement with both eye and mind.

In dance, movement is of prime importance and his or her body is like the paint-brush as it were, the form of which becomes the dance act. The audience responds to the kinaesthetic energy of the dancer as the dancer weaves a certain form that may be experienced by the audience so as to cajole him/her to also dance or at least sense its movement without external activity. Music, likewise, calls upon both dexterity and an "intuition" (a movement of the mind?) insofar as it is related to dance and rhythm. The sounds the listener hears, to the extent that it forms an intellectual coherence and a sense of emotional accord, moves the listener.

In sculpture, the artist is even more physical than the painter would be generally speaking as he or she works muscularly in order to shape his or her material. And as is common to the arts, the resulting sculptural form moves the onlooker causing emotive and intellectual pleasure. The eye of the beholder follows the positive and negative shapes of the material which can be traced around its 
three-dimensionality, creating a kind of "presence" and attraction to the audience.

Poetry, although in the textual form (writing) and in the articulation of the lips (speaking) in auditory form, because (verbal) language is its prime medium, is the least sensory of the arts, debatably so. But writing and speaking are also obviously physical movements. The poet conjures images, both thought-constructs and feelings that potentially yield the same pleasurable delights as enumerated in the other arts. The reader may sense the poems' (narrative or of ideas and feelings) movement in the literal and figurative reading of the poem or text.

Installation art and new media, rather recent phenomena, seem to tend towards sculpture and "ready-mades" in the case of installation art, while new media tends toward film. In these respects, the installation artist is like a sculpturer who places objects requiring both movement and physicality. In the case of the new media artist, he or she would have to use technology, in the form of cameras and the like in order to capture and convey his or her message. In other words there is a physical making, a movement on the part of the artist in both cases. In both cases, as with the above examples, the audience is both moved by the eye, as it were, amongst the various physical objects in the former case; while in the other, the temporal dimensions both in respect of the receptive eye and ear become engaged by the apparently non-existent or transparent moving camera.

A general comment, regarding these disciplines of fine arts, is: 1) The artist wishes to move with and through his/her medium, while the audience, in a sense moves into the medium itself. 2) This list is by no means exhaustive and there are clearly art-forms or styles or movements, like conceptual art, Dada, Bauhaus, performance art, Fluxes and the like where it is unclear where exactly they "fit in" as fine arts, though clearly they are regarded as such. There are many such interventions, some of which are marked by a tendency to the so-called an aesthetic, and even lead to the creation of new sub-disciplines in the arts. The important point is that by in large these interventions tend toward the cloistered self-definition of high, fine art or devalue that as elitist and come close to everyday life, mass, consumer society and the popular arts (film as an outgrowth of theatre, for example, though not "destroying" the former) and craft. 3) It would appear that the higher senses of seeing and hearings are privileged, but by isolating movement here, I engage with the body as a whole and therefore the full gamut of senses. 4) The concept of "movement" does not negate "stasis" in the arts, implied here as a complementary pairing (movement is but relative to stasis and dependent on frames of reference).

With this understanding of art, how might we apply that to developing an understanding of sports? In other words, art may be a lens through which to understand sport, specifically in terms of movement.

There are clearly numerous sports ranging from individualistic to team sports, from ball sports to sports where participants are pitted against nature, aquatic sports to extreme sports and so on and so forth. In most cases, the chosen me- 
dium or sport requires moderate to excessive movement of the body. Like art and perhaps even more so with sport, the senses are engaged and focused in order for movement to be accurate and optimal. In a team sport like soccer for example, movement must be coordinated relative to either players both on ones own team and in relation to the opposition, as well as in relation to the soccer ball. The movement needs to be rhythmical, controlled and creative for the best play to emerge. In an individual sport like judo, which is akin to wrestling, movement has to be economical, powerful and timely in order to out muscle and out wit ones opponent. Sometimes movement is in relation to or in the face of nature which may be hostile, even life threatening as is the case in mountain climbing for example. The list could go on. Clearly for the participant, movement is critical in performing well. From an audience's perspective-the onlooker or viewer-he/she as with art enters the "field of play" as it were, and may intensely lose him/herself in the movement of the athlete. This empathy with the athlete (einfuhlung) as I would call it, requires more than a transfer or movement into the sports act: it opens up the possibility that emotively and intellectually there is a pleasurable effect caused by such viewing. What I am saying is that sport, like art may yield both an emotional and intellectual effect and satisfaction. On an emotional level there is a human identification with the athlete and the spectacle that gives rise to emotions as the game unfolds or moves. Intellectually, there is conscious and subconscious pleasure taken in order, coherence, and skill. By intellectual effect I also mean that sport, like art is not a propositional, verbal sort of knowledge, but rather what may be termed intransitive knowledge.

What we can conclude from this brief account is that movement, rather broadly defined is a significant part of art making and art appreciation and may be extended to include and explicate why movement in sport fascinates and captivates so many people. I shall now describe "physicality" in respect of art and how that applies to sport.

\section{Physicality: The Pre-Discursive Body (As Artist/Sportsperson and Audience)}

Kant (1952) describes the successful artwork as one that involves a playful movement between understanding and intuitions, between that of conceptual and sensory play on the part of the audience. As I understand this, one can describe this "movement" as a physical occurrence in the brain as well as ones relationship between perceptual and conceptual thinking/interpretation. Another way of saying this is to follow Hegel's (1993) definition of art as one that is a kind of midpoint between sensuality and abstraction. Or perhaps less metaphysically, one might take ones cue from Nietzsche (1967: p. 427) who says, "if we subtracted all intestinal fever from lyricism in sound and word, what would be left of lyrical poetry and music?" It is clear for the artist and audience to be receptive to the artwork a certain physicality is required insofar as the art-object is 
an artefact, a text, some kind of form amenable to the senses and ignites emotive and intellectual content to the extent that the physical body that is the work of art leads to these more interior (physical) processes. This would also apply to the artefact as in the form of language, say the poetry text, for language is a medium. It has physical limits and words are physical sounds whose meaning may change over time or in different (physical) contexts. In some ways content is form.

Moreover, the medium that the artist uses and that a sensitive viewer is privy to, is a physical substance. It is owing to working with that medium and in a physical art-world context (considering Institutional theories) that might cause in the audience a certain response, whether it is shock, philosophical reflection, a sympathy for its beauty and so on or even a combination of such reactions/interpretations. In all such cases, there is necessarily a physical component that interacts with ones personhood, which is an amalgamation of the bodily and the less bodily-memory, experience, world-view... I say "less bodily" and not simply "mind" as the latter too constitute a compounded whole that requires material interrelations and the like, that can be dissected and analysed.

It is the physicality of, for example, paint, that coagulates to form an image even in the case of more "abstract" works. The transition from form to content is smooth insofar as physicality transmutes into meaning and the various (physical) combinations of colour, line, texture and so on and so forth are said to represent something or at least be interpreted as an art-object given its (the paintings) context. For it is the art-context, the gallery space and the like that allows the artist to communicate to an audience and thence facilitates an art-repose on the part of the audience when looking at the painting as more than just arbitrary complexes of stuff, but as art. As far as the artist is concerned, the movement alluded to above is precisely a certain physicality.

Now applied to sport, I would say that most sports (chess and others like it less so) require physical exertion, tools in many cases and a physical arena of sorts within which the sport event takes place. One is usually pitied against other "bodies" or at least tries to attain physical accolades within time and space constraints. The prime medium in sport is usually the human body itself through which the sportsperson acts. To the extent that the "move" and "play" is successful, so that physical "move" and "play" becomes a successful sports-act or an exhibition of what one might call coherent form. The intertwining of sensuous, instinctual and conceptual "components" together constitutes a willed action reaching the limits of physical possibility. I include the conceptual "component", because the sports-form and the context in which it takes place, contain both information about the individual performer and the times in which he/she lives. The sportsperson, like the artist reflect the times he/she is living in, sometimes irrespective of their personal goals and vision and sometimes perhaps more consciously congruent. The signs of culture-its material form-are thus the physical embodiment of meaning within a given historic context and a summation of the historic moment or merely its by-product. There may be no trans-historical 
sign, text, form or physicality and no trans-historical interpretation thereof. Nevertheless, the sheer physicality of the sign—sport as with art-suggest that it can be "mined" for content. However, this "content" is itself embedded in a system of signification, so that at best one should simply maintain a post modern "position" wherein Logos is not some kind of Archimedean point from which to view culture and thus interpret art and sport. Furthermore, since the nature of physicality is that it is constituted by parts and related to other things, so we can but "play" with styles, forms and signs without final meanings or truth. In this sense, one could envisage a hybrid of both art and sport. This then deconstructs the idea that there is an essence to either art or sport-a metaphysical point that defines each separately-with the idea that signs by virtue of being a language-are interrelated.

Sports' physicality expresses and communicates in ways easily understandable the idea that life itself is one of both play and struggle. While one may perceive this in an artwork, the fact that sports perhaps more than the arts is a matter of entertainment, communicates certain values to a larger audience than the arts. The physicality may mask these values in the same way an artwork's underlying message is "beneath" the physical movement, sound, image... At the same time the physicality of sport, like art is the mechanism whereby one can "read" or intuit something else. This is similar to what Derrida $(1972,1976)$ had to say about his view of language, namely that there is an "other" beyond the text. That "other" is yet another physicality, as there is no essence to which we can ascribe metaphysical being and ontological presence. Thus as in theory so in sport: ongoing movement between, within and in relation to others, so that this "endless physicality", however "deep" (in interpretation) one may delve-insofar as something is expressed and articulated, that is, assumes physicality-one does not reach an “origin". Just play. Just struggle. And sport, like art reveals that tension.

\section{Aesthetics and Extra-Aesthetics (As Artist/Sportsperson and Audience)}

The invention of the aesthetic as it pertains to art (and later to nature and now more recently, to the everyday) may have lost currency in the evaluation of art, but I believe it is still a significant tool to appreciate, understand and enjoy art. That is, insofar as we attend to the possible beauty of the artwork, it assists one in understanding what the artist is trying to do when he/she makes some part of the work "just right". It explains what we mean by praising art as not merely practical and instrumental, as not simply being an object to be bought and sold and why we may stand transfixed before a work of art as its "presence" causes us to have an experience. This experience is aesthetic to the extent that we attend to the works beautiful arrangement-its composition, colour, line, texture, scale and other properties in various relationships and proportions.

Nevertheless, with Dewey's (1958) idea of "an experience", of the aesthetic being pervasive, and the critique of both some analytical and continental philo- 
sophers of the aesthetic, it appears we have two options: To dispense with the term altogether as applying to art or to reintroduce the term and reconstruct the aesthetic with reference to a number of experiences, art included. I side with the latter option.

Dewey (1958) tried to integrate the aesthetic within the flux of life itself. He does this by arguing that "an experience" as distinct from just ordinarily doing/experiencing things, is an experience of a certain "intensity", "closure" and "heightened sensibility". Accordingly, aesthetics applies to a number of possible experiences and not necessarily that of art. Some, such as Danto (1992, 1995) and Goodman (in Shusterman, 1997) as well as continental philosophers such as Derrida (1978), Barthes $(1957,1977)$ and Bordioue (in Culler, 1983) critique the idea of a certain aesthetic experience in art. Broadly speaking Danto and Goodman argue that art is concerned with certain "symbolic structures" that are not derived merely from "what the eye can decry" (Danto, 1995). The continental philosophers mentioned above generally explain art in terms of ideological structures that undermine mere aesthetic considerations. Following from this, I would argue that both aesthetic and extra-aesthetic, ideological considerations are important to art and art-like experiences and as mentioned hitherto form a complementary pairing. In simple terms: we may say art is partially aesthetic; we may say that the aesthetic is not confined to art and lastly that with some art, its meaning tends more to the extra-aesthetic than the aesthetic. Measuring to what extent sport, like art tends to one "pole" or the other is not really possible, as one either sees them as aesthetic, as instances of beauty or as "revealing" (though sometimes concealing) ideological, non-exhibited meanings. In fact, I would claim that simply equating aesthetic sensibility with the ideological is dangerous or more perspicaciously, not knowing that there is such a distinction in the first place, may be dangerous.

One can envisage this hiatus as in the well-known vase-two faces image wherein one can either see two faces or a vase, though both are true. Similarly, one can see art or sport as aesthetic objects or perceive the "background" ideological features-history, science, religion and so on and so forth. Without making this distinction, the transparency of the medium, and of the aesthetic meaning is assumed and believed to be a fact that reveals a particular ideology. Rather it is married to a particular historic moment. One needs to realize the aesthetic-artistic does not, however, necessarily correspond to a certain "form of life". It is unclear whether the aesthetic or the extra-aesthetic is dominant. The refinement that recognises this dual interpretive schema is, I believe the first step in not putting art on a pedestal and the first step in recognising the art in sport. This is not to devalue art perse, but points to the fact that it can be co-opted and manipulated by some extra-aesthetic concerns that in my estimation may not be good, which is not to render art-aesthetics itself bad. Similarly sport itself is not bad if it is a mere "play" of an ideologically crooked system. Therefore I am isolating both art and sport as in general culturally edifying. Perhaps that is why I 
am basically against censorship in the arts in general and enjoy watching soccer matches, for example between rival nations in "real" life.

There is a general resistance in academic circles to theorise around sport as it is regarded as low-brow culture compared to the arts. However, the new-sub discipline in aesthetics, namely aesthetic of the everyday, suggests that we can apply art-like perception to sport. My contribution is thus to extend our understanding of sport via particular artistic frameworks.

\section{Emotion (As Artist/Sportsperson and Audience)}

Art is not only something intellectual, a logical abstraction. Neither is it simply a meaningless physical labour. Art is rather the bridge that connects concept and physicality, the extra-aesthetic and the aesthetic. It is a kind of creation that energises matter; matter itself that obeys seemingly fixed laws. In the process of creation, emotions are born, the energy that brings together concept and percept. And so when someone apprehends the painting, dance, music or whatever they too may feel what the artist felt qua Tolstoy. That is the common assumption of the relationship between the artist, the work and the audience. The truth is that the audience may not appreciate an artists' work. Or another scenario: the audience may like the work, but the artist has no idea what he/she may be saying. In either case the artwork may impede communication (at least at that time for those people-Van Gogh being the quintessential example). That is not to say that an artwork may not outlive the artist and become pertinent at a later time. Again, herein lies the common practice whereby some artists and their paintings, for example become canonised artists and their work, masterpieces, according to the caprices of history and its off-spin, art history (or vice-versa), and may in turn be completely contingent, highly relative and subjective. This does not mean art offers no knowledge; only that what is considered as such can only claim a "fact" as a partial truth and a "value" as a relative truth. But these partial truths become cultural practice and accepted norms. Put crudely: it is what is taught. Nevertheless, I hold that art has something of value, particularly on the emotional level as a bridge between thoughts and action in the imaginative life.

The emotional value of the practice of art is that culturally, and thus hopefully by implication, in the context of a persons life generally, one might say that art "softens attitudes". Art has the potential to allow an inquiring mind to explore both imaginatively and symbolically art itself as well as the overlaps with other fields of inquiry - philosophy, science, religion and so on which in turn may reflect a life-attitude. At the same time art is just craft, a particular skill aimed at solving particular problems so far as medium and technique are concerned.

We shall compare these findings or observations to sport. Sport is not only something intellectual, a logical abstraction (the analogue of "right thought" is "right action"). Neither is it simply a meaningless physical labour. Sport is rather the bridge that connects concept and physicality, the extra-aesthetic and the 
aesthetic. Sport is like a bridge in that it brings people together, the heart overcomes perhaps national, racial, gender and other differences and unites. Consider the significant positive role soccer, rugby and cricket has had for South Africa, for example notwithstanding a checkered past and sports' sordidly implicated.

For the sportsperson and this need not apply simply to elite athletes only when a person is involved in a sport he/she expresses himself or herself like an artist. I say this, because to do a sport involves mental focus, an almost non-focused focus (a "meditative shutting out the analytical" as Noakes (2010) describes it) and physical skill (depending on the kind of sport) and to the extent that there is a marriage between the "zoning in" and the physical alertness and deftness, to that extent the sportsperson expresses himself/herself which may result in a "nice move". Is this not what often needs to take place to paint, to play music, to dance, to sculpt and so on? I would say, though I have but hinted at the process at work, this appears to be the case. To express is an emotional movement from within to without (the sensible), which is not to say that it cannot express ideas. I oppose Best's $(1978,1986)$ argument that sport can have no content and cannot talk about life issues whereas art does. I disagree, because if it is true that the sportsperson can be said to express in the way an artist does in many respects, then it is "about something". "A nice move" is an aesthetic move and thus only about itself, but it is also a sign which can come to mean many things, ranging from the political, to the psychological, to the religious, to the scientific and so on and so forth. This accounts for the potentially multi-dimensional emotional flavour of sport, like art.

\section{Game and Play (As Artist/Sportsperson and Audience)}

It would appear that sport is more associated with the concept of games then art, given the fact that rules are a necessary part of all sports. However, if we look at for example the institutional theory of art by Dickie (1969, 1971, 1974), suffice to say that the first part of his formulation as to the definition of art requires in some way or other the presentation of an artefact. This idea can be thought of as a rule. The second part of Dickie's $(1969,1971,1974)$ formulation is that this artefact ought to be presented to the so-named art-world. Danto $(1992,1995)$ extends this and claims that the art-object finds meaning in relation to the practise of art theory and art history. The upshot of this is that, 1) The rule that an object needs to be presented and 2) that this takes place within a certain art and (other) context(s) may be another way of saying that art is a game that is played; it is a social practise.

Moreover, each art-form or discipline has a certain logic, which is to say a rule governess that describes what the medium can and cannot do. Clearly, there are particular aesthetic characteristics of an individual style and that of a particular time and place; however art is marked by continuous play and change so that the game itself takes place in ever nuanced complexity.

The beauty of the game of art is that this play is both self-referential and im- 
plies content and hermeneutic play. This then is another instance of aesthetic and extra aesthetic complimentary pairings, but here I highlight this paradox as the engine that generates meanings and enjoyment garnered in art as a playful, if at times a serious game. More obvious connections between art and games are that art takes place in some kind of consecrated spot: an arena, stage and studio, presented in a gallery, conservatories, museums and the like, for example. In fact, actors and musicians, to use another example, are said to play and when the latter do indeed play, they are referred to as players. Furthermore, the very creativity in the arts is marked by the capacity to, on the one hand, play with different sensory arrangements, if you like and on the other hand, the open-ended signification of those sensory-signs. In other words, the artist may use existing codes, which are already established painting styles, for example, to convey a supposedly corresponding meaning. However, the "game-changers" develop original languages or sign systems that both have aesthetic/formal newness and open-ended meanings. In these terms, the game of art evolves.

The question is: are rules a part of the art-game to the extent they are inherent in sports games? Rules are related to morality, in terms of their prescriptive logic. Insofar as questions of morality, ethical imperatives, have been perennially associated with art, it would seem that we somehow expect art to conform to some set of moral truths. At the same time, art is an imaginative activity and the aesthetic, precisely amoral. This paradox, rather than a contradiction reflects the nature of the art game: that it is at once an expression of our highest values and at the same time, an assessment and critique of those values. In this sense, I would not speak of hard and fast rules in art, but a tacit cultural understanding that some things in art simply won't do. What I mean by this is not a conservative, institutional censorship, but rather acknowledgement that we always need to engage in the discussion/game of the boundaries of art aesthetics as an ethical imperative (that is, in order to improve the conditions of life).

Sports are more readily understood as games. They are distinguished by rules that define what can and cannot be done in the context of the game played. But they do not determine its dramatic element, their aesthetic value and their meaning. Each sport, like each art-form requires a unique set of skills and aesthetic appreciation of their meanings. Both are self-referential, inimical to a particular sport/art, as well as revealing content, that is extra-aesthetic, ideological meanings. "A good play" thus both denotes something done is respect to excelling in the context of the game itself, as well as a value that agon and arête in itself imply in the context of the life-world itself. In this sense, sport, like art at one and the same time is amoral (the move only makes sense or has relevance as part of a game, the "unreal") as well as moral (the move suggests an ethical, cultural meaning or standard).

One might at this point also ask, rules aside, whether sport as a game is more concerned with winning and competition than the arts? If that is so, how can art assist in understanding sport (theory and practice)? Note that the art-world is 
such that the artwork assumes cultural value as a result of art-world players that "make" culture (I realise this is rather tautological) that then has spin-off effects commercially and economically. That the artist does in some way compete with his/her contemporaries if one chooses to play the game of art, as it were. That prestige, marketability and monetary value is an epi-phenomenon of larger institutional (artistic and other institutions) bodies that give the artist and his/her work "value" or cultural capital and the like. In philosophical terms, we may say, following Nietzsche that there is a kind of "will to power" inherent in making, showing and saying-that artistic form and artistic forming-are about influencing and "making a move" that will yield a kind of victory-if not in respect to the "art world" itself than (at least) in the creation of an art-piece itself. In sum: there is sport to art.

If the above account is tenable, then clearly art and sport are related, specifically, in terms of the desire for perfection not only in "the move", "the act", but also in securing victory, prestige and for some "world records". People aspire to such sporting heights, because winning is one way in which we feel that life has meaning, that others have pushed us constructively, that one have pushed oneself and achieved something tangible and perhaps most significant, that one has overcome barriers in the attainment of that sports feat. And yet, like art, both are unreal, imaginative constructions; they are games. In this respect, and applied to life, it is not simply about winning that is important, but the values through the game that are learnt in the context of a way of communing with others. In this sense, art and sport are radically cultural and radically about and for life.

\section{Cultural (As Artist/Sportsperson and Audience)}

Connecting the life-world with the cultural, as indicated above, is to traverse the seeming boundary between art and life. This has been a crucial sticking point in art: Is it arts-for-arts sake or does art have something pertinent to say and do in relation to life itself (not just amalgamating with politics, economics, philosophy and so on) but as art for life? Consider the advent of Western modernism: realist artists tried to capture the "facts" of reality; impressionist artists, the passing effects of light, time and movement negating at the same time arts' hankering after the religious image, myth or history; an Expressionistic critique of contemporary values and a refuge in the tumultuous soul... In all these cases, there is an attempt to reach out or reflect on the everyday. Of course, there is a simultaneous arts-for-arts sake mantra, because in each instance innovation is peculiar to that particular art-form, a certain artistic style and artistic prerogatives and methods over and above other (extra-aesthetic) concerns are at play. Moreover, even examples such as Fauves, Cubism and later Abstraction, although seemingly exclusively about technical matters and problems in art itself, still harbor "content". Newman, for example spoke about the significance of his art and Abstract Expressionism in general not in purely formalist terms but as painting about something. 
With post modernism, beginning in art practice possibly with Pop art, though influenced by modernist prerogatives and certainly Duchamp's declaration of the "ready-made", it seems to me to be an attempt to integrate "high" culture with "low" culture in a strategic attempt to ultimately argue that life itself is art, both in the aesthetic sense and conceptually. In other words: Warhol's Brillo Boxes $^{1}$ (1960) is indistinguishable from "real" brillo boxes; Duchamp's "ready-made" such as his Fountain ${ }^{2}$ (1917), a porcelain urinal that is indistinguishable from a "real" one and various Pop art strategies that question the "sacred", "deep" mark of the artist-all point to: 1) the potential to see aesthetics pervasively and 2) that life itself-its experiences, events, arenas can be taken as a metaphor or conceptual game in much the same way that we usually reserve art to our interpretive "gaze".

One way in which art may then be experienced in the future is to firstly be acquainted with its history, theory and practice and then to deconstruct that "cultural game" only in order to reconstruct it as instances of play in other cultural frameworks. In this respect, art "reaches out" to sport (or perhaps even the other way around), in order to enrich our aesthetic and conceptualizing modalities. This then would serve to render culture both widespread, considering sport is so easily accessible, and assisting one in make that necessary distinction between aesthetics and ideology. That is, insofar as one is not simply duped by images (the unconsciousness of the aesthetic as it were) and sees it as corresponding to an equally fixed conceptual form or world-view, so one is in a "position" of uncertainty, creativity and openness. I believe such values if part of a moving, cultural field are appreciated, and then it may have positive spin-offs in other domains, many of which not usually deemed as culture may then be considered so. It is like the proverbial Zen master who meditates as he walks and sweeps and cleans the floor. I have not resorted to a metaphor willy-nilly, for much of what I have said about the lack of fixed knowledge (relationship between sign and referent) and the fluid nature of culture in theory and practice as well as the incommensurate nature of complementary pairings, means that defining "reality", "life" and "culture" is best "captured" by way of metaphorical expression. And to the extent that a culture uses metaphor, so it can dream, make connections and recognize unity amidst difference.

The rather philosophical reflections above have particular applications, for insofar as art produces meaning, even if at times an ineffable one, by way of metaphor it may teach us to see in sport a similar metaphorical play. That is, sport is both about itself and not about itself. A soccer match is just a soccer match. But it is other things. It is artistic or at least can be experienced aesthetically. It reveals and conceals social realities which in turn have philosophical, ideological, economic, psychological and other "texts" seemingly "therein". It may be simply entertaining and about a certain kind of skill-physically-mentally-but that "presence" may yet conceal an "absent" such as these other "texts". The soccer ${ }^{1}$ Museum of Modern Art collection, New York.

${ }^{2}$ Installation Exhibition, Stockholm, 1963. 
match may end in its allotted time, but it is part of a process of ongoing cultural narrative(s), and it is not clear to me whether that process is necessarily ideal. One could always ask why money used for sport might not be better spent in certain societies. And the same may be asked of art for that matter. I believe, however that art and sport can be cultural bridges that bring people together, wherein discussions around beauty and a critique thereof may cut across boundaries. Debate, positive interaction and the forming of paradigms are in my estimation, in general terms a good thing. Though one may not reach a trans-historical all-encompassing set of truths, one tends toward more knowledge or at least an understanding (of ourselves and others and of both the inner and outer universe) that should equip one to appreciate and develop an aesthetic and extra-aesthetic awareness firstly in art and thence in sport (and back again).

Considering the above six points of connection, it is reasonable to consider art aesthetics and the everyday aesthetics of sport as relational. More specifically, that art aesthetics may direct one to an understanding of the aesthetics of sport. If this is the case, it may be that a significant and beneficial area of study ought to consist of seeing whether teaching art to sportsmen and woman may actually improve their sports performance.

\section{Conflicts of Interest}

The authors declare no conflicts of interest regarding the publication of this paper.

\section{References}

Barthes, R. (1957). Mythologies. Paris: Le Seuil.

Barthes, R. (1977). From Work to Text. In Heath, S. (Ed.), Image-Music Text (pp. 155-165). London: Fontana.

Best, D. (1978). Philosophy and Human Movement. London: Allen \& Unwin.

Best, D. (1986). Sport Is Not Art: Professor Wertz's Aunt Sally. Journal of Aesthetic Education, 20, 95-98. https://doi.org/10.2307/3332697

Culler, J. (1983). On Deconstruction. London: Routledge.

Danto, A. C. (1992). Beyond the Brillo Box. New York: Noonday.

Danto, A. C. (1995). After the End of Art. Princeton, NJ: Princeton University Press.

Derrida, J. (1972). Structure, Sign and Play in the Discourse of the Human Sciences. In R. Macksey, \& E. Donato (Eds.), The Structuralist Controversy (pp. 247-272). Baltimore, MD: John Hopkins University Press.

Derrida, J. (1976/1967). Of Grammatology (Translated by Spivak, G.C.). Baltimore, MD: John Hopkins University Press.

Derrida, J. (1978/1967). Writing and Difference (Translated by Bass, A.). Chicago, IL: University of Chicago Press.

Derrida, J. (1984). Deconstruction and the Other: An Interview with Jacques Derrida. In R. Kearney (Ed.), Dialogue with Contemporary Continental Thinkers (pp. 105-113). Manchester: Manchester University Press.

Dewey, J. (1958/1934). Art as Experience. New York: Putnam’s Sons. 
Dickie, G. (1969). Defining Art. American Philosophical Quarterly, 6, 210-241.

Dickie, G. (1971). Aesthetics: An Introduction. Indianapolis, IN: Pegasus.

Dickie, G. (1974). Art and the Aesthetic: An Institutional Analysis. Ithaca, NY: Cornell University Press.

Dowling, C. (2010). The Aesthetics of Daily Life. British Journal of Aesthetics, 50, 226-242. https://doi.org/10.1093/aesthj/ayq021

Hegel, G. W. F. (1993). Hegel: Introductory Lectures on Aesthetics (Translated by Bosanquet, B.). Harmondsworth: Penguin.

Kant, I. (1952/1790). The Critique of Judgment (Translated by Meredith, J.). New York: Clarendon.

Kripke, S. (1982). On Philosophical Paradigms. London: Blackwell.

Melchionne, K. (2011). Aesthetic Experience in Everyday Life: A Reply to Dowling. British Journal of Aesthetics, 56, 437-442. https://doi.org/10.1093/aesthj/ayr034

Melchionne, K. (2013). The Definition of Everyday Aesthetics. Contemporary Aesthetics, 11, 35-51.

Nietzsche, F. (1967). The Birth of Tragedy and the Genealogy of Morals (Translated by Golffing, F., 3rd Ed.). New York: Anchor.

Ratiu, D. (2013). Remapping the Realm of Aesthetics: On Recent Controversies about the Aesthetic and the Aesthetic Experience in Everyday Life. The Central European Journal of Aesthetics, 50, 3-26.

Saito, Y. (2007). Everyday Aesthetics. Oxford: Oxford University Press. https://doi.org/10.1093/acprof:oso/9780199278350.001.0001

Saito, Y. (2010). Future Directions for Environmental Aesthetics. Environmental Values, 19, 373-391. https://doi.org/10.3197/096327110X519880

Shusterman, R. (1997). The End of Aesthetic Experience. The Journal of Aesthetics and Art Criticism, 55, 29-41. https://doi.org/10.2307/431602 